\title{
Collection of waste batteries in Portugal and Brazil
}

\author{
N. Vieceli, F. Margarido \\ Lisboa, Portugal, \\ F. Durão, C. Guimarães \\ Instituto Superior Técnico (Univ. Lisbon), Lisboa, Portugal, \\ C. A. Nogueira \\ Laboratório Nacional de Energia e Geologia, I.P. (LNEG), Lisboa, Portugal,
}

Center for Innovation, Technology and Policy Research - IN+, Instituto Superior Técnico (Univ. Lisbon),

\begin{abstract}
The legal aspects governing the disposal of used batteries were established in the nineties of the last century in Brazil and Portugal. In Brazil the law establishes the implementation of a reverse logistics system of this waste, similar to the system of Portugal, in which there is an extended producer responsibility. Portugal, subjected to the targets set by the European Union, has increased collection rates, with emphasis on the role of management entities. In Brazil, progress and the development of strategies to increase the collection rate have been observed, nevertheless, challenges associated with the increase of the coverage of the collection of batteries and also the public information about the disposal are relevant, as well as combating irregularities. Moreover, given the growing concern over the shortage of raw materials, proper management, including the collection and recycling of these wastes, can be seen as an important opportunity for both countries.
\end{abstract}

\section{INTRODUCTION}

The appearance of batteries brought considerable advance from the technological point of view, however, their production on an industrial scale and low cost led to an increase in consumption, which resulted in a new paradigm about their disposal because, despite their innocent appearance and small size, batteries are now a serious environmental problem, since in most cases they are disposed of inadequately (Gomes \& Melo 2006).

The process of recycling used batteries begins in their collection stage and the difficulties in this step are the main challenges to recycling, particularly in small countries (Nogueira 2001). In this context, the efficiency of the collection process for used batteries and the efficiency of the metal recovery process can be considered factors that will affect the overall environmental and human health impacts of battery systems (Morrow 2001). According to Nogueira \& Margarido (2012), the best approach for end-of-life management of used batteries is the recycling, mainly for environmental reasons but also motivated by resources preservation and, in some cases, by economics profits.

The main objective of this work was to study the systems of recovery and management of endof-life batteries developed in Portugal and Brazil, mainly regarding the collection, once studies on the subject are scarce. The evaluation of the evolution thereof and the identification of the existing challenges and opportunities for improvement, is relevant work for more than just this two countries, since the management of this waste is a global challenge. 


\section{Wastes: Solutions, Treatments and Opportunities}

Editors

Cândida Vilarinho \& Fernando Castro

University of Minho, Guimarães, Portugal

Mário Russo

Polytechnic Institute of Viana do Castelo, Viana do Castelo, Portugal

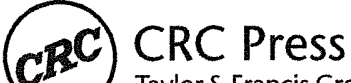

Taylor \& Francis Group Boca Raton London New York Leiden

CRC Press is an imprint of the

Taylor \& Francis Group, an informa business

A BALKEMA BOOK 